\title{
Safety of users in road evacuation: simulation of a user refuge area
}

\author{
A. Vitetta \& V. Assumma \\ Department of Computer Science, Mathematics, \\ Electronics and Transportation, \\ Mediterranea University of Reggio Calabria, Italy
}

\begin{abstract}
In this paper some results obtained in the SICURO research project are discussed, especially with regard to users who evacuate with motorized modes due to a forthcoming disaster and their movement to an area of refuge. Evacuation produces temporary over-saturation of some supply components and creation/dispersion of queues, in particular upcoming and moving in the refuge area. To analyse this event two problems must be explored: access to the refuge area and the internal organization. The problems are studied by using deterministic and stochastic queuing theory. Calibration data were obtained from a real experiment executed in the urban area of Melito Porto Salvo in the province of Reggio Calabria (Italy). Finally a computer application was carried out to reproduce all the evacuation phases observed in the experimental test site of Melito Porto Salvo.
\end{abstract}

Keywords: safety, evacuation, refuge area, queue, simulation.

\section{Introduction}

In evacuation plans the territorial analysis phase is very important, since this analysis is the basis for required action to take in an emergency.

This paper deals with the study of refuge areas. Such areas, situated far from high-risk sites, are preventively identified in the region. In Italy each prefecture, together with the Civil Protection Agency [1], defines some general characteristics that the emergency areas must have, according to their purposes. There are three types of emergency areas: concentration areas, refuge areas and reception areas. 
In concentration areas there are vehicles, materials and human resources required for the emergency. Refuge areas are places considered safe, from a particular event, in which the population has to evacuate pre- or post-emergency. Reception areas are the refuges of the population that have to abandon their own residence for longer periods, depending on the emergency itself.

In the literature, to our knowledge there are no specific models for simulating emergency conditions and refuge areas in particular. This paper deals with the specification, calibration, validation and testing of models used in the literature for simulation and design of refuge areas.

After a short introduction to the problem and an updated review of current models in the literature (section 2), we present a real test case (section 3), an application of the models to a refuge area (arrivals and internal organization) (section 4) and some comments and indications for further developments (section 5).

\section{Models}

The development of models for emergency conditions in transportation systems has not received much attention in the literature [2]. In [3] large-scale emergencies are treated when a nuclear event occurs, [4] and [5] deal with urban systems when general hazards occur, while [6] and [7] cover buildings during fires.

In general, there is no systematic analysis of general risk theory applied in transportation systems. When an event occurs in a system or is bound to happen in the short term, evacuation measures must be applied and in some cases have to be designed in real time [2]. In emergency conditions the models and algorithms specified and calibrated in ordinary conditions [8-11] cannot be directly applied.

The methodologies to represent the behaviour of real systems can be traced back to two different approaches: simulation or "what if" (what happens if); design or "what to" (what to do for).

Simulation differs from design because in design the various scenario hypotheses are produced through models and are analyzed and assessed with an optimization procedure in respect of certain constraints. Simulation models can be classified by variables such as [12]:

- Static/Dynamic: in dynamic models, time is an independent variable;

- Continuous/Discrete: in a continuous model the system state can continually change in time, while in a discrete model changes occur only in certain instants;

- Deterministic/Stochastic: in stochastic models, random variables and probability distributions are also inputs.

Discrete models can be classified into discrete times or discrete events. In discrete time models, time is a succession of intervals of fixed length; in discrete event models the state's changes are recorded as events happen.

Simulation models [13] can also be classified by level of detail:

- models are microscopic if they describe both the entities of the system and their interactions with a high level of detail; 
- models are mesoscopic if they describe the entities of the system with a high level of detail, although activities and interactions are described with a small level of detail in comparison to microscopic models;

- models are macroscopic if the entities and activities are described with a low level of detail.

High-fidelity microscopic models faithfully reconstruct reality but are expensive to develop and run due to the complexity of the logical relationships and number of parameters.

In the literature, terminal simulation models are classified by their characteristics; they are mostly dynamic, discrete and stochastic (Tab. 1).

Table 1: Characteristic of terminal simulation models.

\begin{tabular}{|c|c|c|c|c|}
\hline & Static/Dynamic & Continuous/Discrete & Deterministic/Stochastic & Microscopic/Macroscopic \\
\hline Bielli et alii , 2005 & $\mathrm{D}$ & $\mathrm{D}$ & $S$ & MI \\
\hline Bruzzone et alii, 1999 & $\mathrm{D}$ & $\mathrm{D}$ & $S$ & \\
\hline Cartenì et alii , 2005 & $\mathrm{D}$ & $\mathrm{D}$ & & MI \\
\hline Degano, 2003 & $\mathrm{D}$ & $\mathrm{D}$ & $\mathrm{D}$ & \\
\hline $\begin{array}{l}\text { Fortino et alii, 2001; } \\
\text { Legato and Mazza, 2001; } \\
\text { Gaudioso et alii, } 1999\end{array}$ & $\mathrm{D}$ & $\mathrm{D}$ & $S$ & \\
\hline $\begin{array}{l}\text { Gambardella et alii, } 1996 \text { - } \\
\text { 2001; Bontempi et alii, } \\
\text { 1997; Mastrolilli et alii, } \\
1998\end{array}$ & $\mathrm{D}$ & $\mathrm{D}$ & $S$ & \\
\hline Hartmann, 2004 & $\mathrm{D}$ & & $S$ & \\
\hline Kia et alii , 2002 & & $\mathrm{D}$ & S & \\
\hline Liu et alii , 2002 & & & $\mathrm{D}$ & MI \\
\hline $\begin{array}{l}\text { Rizzoli et alii, 2002; } \\
\text { Gambardella and Rizzoli, } \\
2002\end{array}$ & $\mathrm{D}$ & $\mathrm{D}$ & $S$ & \\
\hline $\begin{array}{l}\text { Shabayek and Yeung, } \\
2002\end{array}$ & & & $S$ & MA \\
\hline Yun and Choi, 1999 & $\mathrm{D}$ & & D & \\
\hline
\end{tabular}

The models we use to simulate a refuge area are the same as those used in the literature for terminals.

This paper proposes the use of traffic flow theory and in particular (Figure 1):

- deterministic queuing theory, by means of a macroscopic deterministic continuous simulation model, to simulate access to the refuge area;

- $\quad$ stochastic queuing theory, by means of a microscopic deterministic discrete event simulation model, to simulate the internal organization of a refuge area.

The upcoming flows are the input of the simulation models: this data are obtained from supply-demand interaction $[14,15]$. The output of macroscopic deterministic continuous simulation models used to simulate access to the refuge area is the input for microscopic deterministic discrete event simulation models used to simulate the internal organization of a refuge area. 
A queuing model is used to approximate a real queuing situation, so queuing behaviour can be analysed mathematically. It can be deterministic (demand and service are treated as continuous variables described by flow rates which vary over the time and space domain) or stochastic (random variables and probability distributions are also inputs).

Access to the refuge area

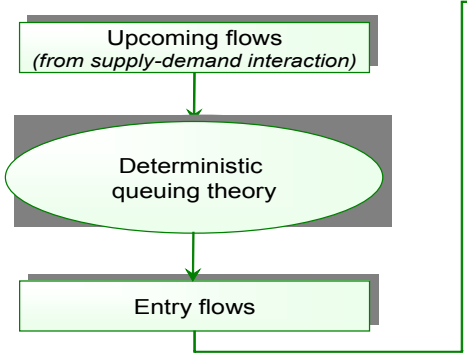

\section{Refuge area internal organization}

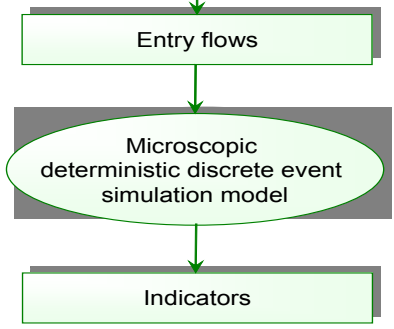

Figure 1: $\quad$ Structure of the proposed models.

The deterministic component of traffic is founded on the fluid theory of traffic in which demand and service are treated as continuous variables described by flow rates which vary over the time and space domain.

The principal characteristic of the phenomena schematized with this theory is that in an interval the upcoming flow is superior to the capacity of the system (Figure 2); in the remaining periods of time, the flow is below capacity (a typical example is a temporary block of a road for a few minutes). The functions that describe vehicle arrivals and departures are known and defined deterministically.

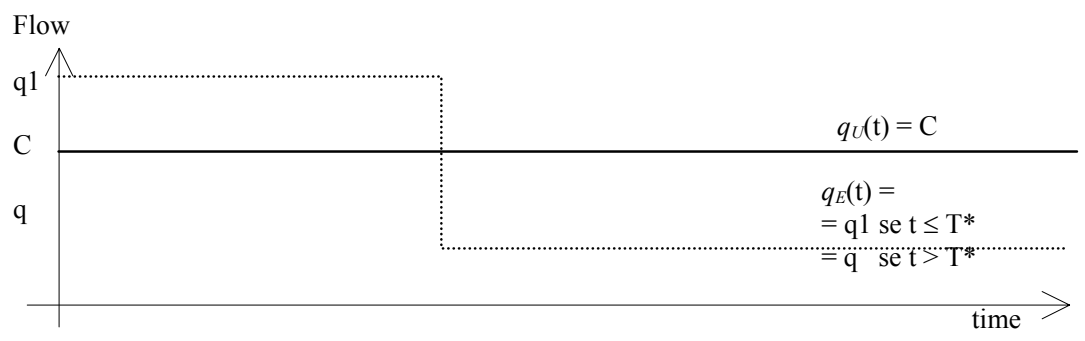

Figure 2: Oversaturation phenomena: deterministic approach.

In temporary oversaturation phenomena, the main system variables are:

- $\quad$ capacity $\mathrm{C}$ of the infrastructure under ordinary conditions;

- $\quad$ vehicular flow $q$ in transit under ordinary conditions $(\mathrm{q}<\mathrm{C})$;

- vehicular flow $\mathrm{q}_{1}>\mathrm{C}>\mathrm{q}$ under temporary oversaturation phenomena;

- $\quad$ interval of time $\mathrm{T} *$ in which $\mathrm{q}_{1}>\mathrm{C}>\mathrm{q}$. 
The general aggregate indicators of the system are:

- maximum queue length (number of vehicles) $\mathrm{N}_{\mathrm{Max}}=\left(\mathrm{q}_{1}-\mathrm{C}\right) \mathrm{T}^{*}$

- finish queue time

$$
\begin{aligned}
& \mathrm{T}_{1}=\left(\mathrm{q}_{1}-\mathrm{q}\right) \mathrm{T}^{*} /(\mathrm{C}-\mathrm{q}) \\
& \mathrm{R}_{\mathrm{T}}=\left(\mathrm{q}_{1}-\mathrm{C}\right) \mathrm{T}^{*} \mathrm{~T}_{1} / 2 \\
& \mathrm{~N}_{\mathrm{R}}=\mathrm{C} \mathrm{T}_{1} \\
& \mathrm{R}_{\mathrm{M}}=\left(\mathrm{q}_{1} / \mathrm{C}-1\right) \mathrm{T}^{*} / 2
\end{aligned}
$$

- total number of users with delay

The stochastic component of delays is founded on queuing theory (Figure 3 ) which defines traffic arrival and service time distributions $(f(C)$ and $f(q)$ ). Appropriate queuing models are then used to express the resulting distribution of the performance measures.

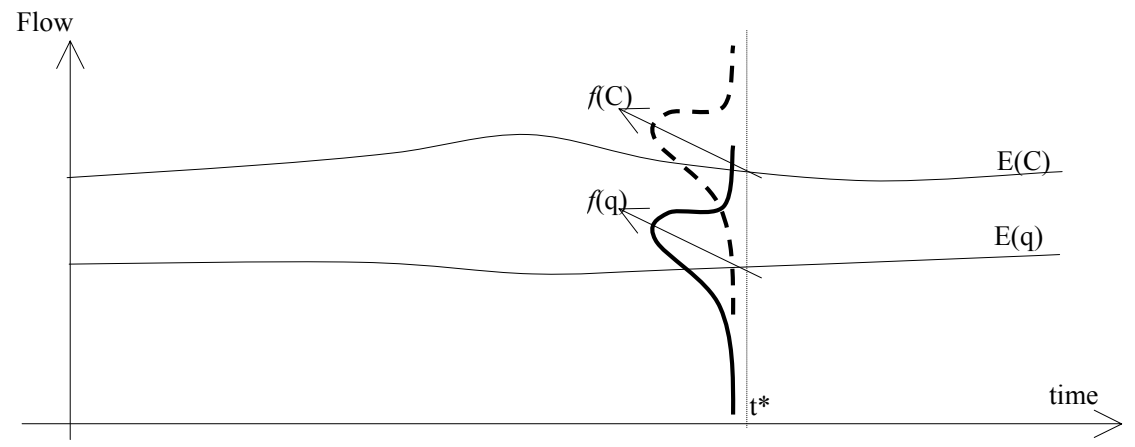

Figure 3: Oversaturation phenomena: stochastic approach.

Stochastic queuing theory is applied when average upcoming vehicular flow is greater than system capacity in a few moments (a typical example is a motorway tollgate).

The averages of vehicle arrivals and departures are known and constant. The real values are random and they vary around the mean. This variation can create delays or queues.

The main system variables are:

- average flow q of vehicles in the system;

- average capacity $\mathrm{C}$ of vehicles in the system;

- average capacity $\lambda$ of vehicles served in the system;

- number of serving channels $\mathrm{m}$.

For a single serving channel $(\mathrm{m}=1)$ the aggregate indicators of the system are:

- average user number in the system

$$
\begin{aligned}
& \mathrm{N}_{\mathrm{S}}=\lambda /(1-\lambda) \\
& \mathrm{L}_{\mathrm{q}}=\lambda^{2} /(1-\lambda) \\
& \mathrm{T}_{\mathrm{S}}=1 /(\mathrm{C}-\mathrm{q}) \\
& \mathrm{T}_{\mathrm{q}}=\mathrm{q} /(\mathrm{C}(\mathrm{C}-\mathrm{q}))
\end{aligned}
$$

- average queue length

- average waiting time

- average queue time

Also for multiple serving channel $(\mathrm{m}>1)$ the general aggregate indicators can be defined. 
Microsimulation is the modelling of individual vehicle movements for the purpose of assessing the traffic performance of highway and street systems, transit, parking and pedestrians. The last few years have seen a rapid evolution in the sophistication of microsimulation models and a major expansion of their use in transportation engineering and planning practices.

To reproduce the real trial to which the vehicle is subject once it arrives at the refuge area we use a procedure implemented by commercial "Arena" software of Rockwell Software. Arena is a microscopic discrete events simulator based on SIMAN language. It combines the utility of high-level simulators with the flexibility of general-purpose programming languages (Visual Basic, C). The step-by-step procedure implemented in Arena performs a series of instructions, providing, at the end of simulation, the allocation of vehicles in the refuge area.

A sequence of events and activities that describe the process is presented in Figure 4, which explains the life of vehicles from access onto the refuge area to parking. Below the figure is a summary of the information that the software elaborates for each block, so as to clarify the meaning of the terms that appear in the figure. Details of the implementation language and definitions of data and variables can be found in the program manual [16].

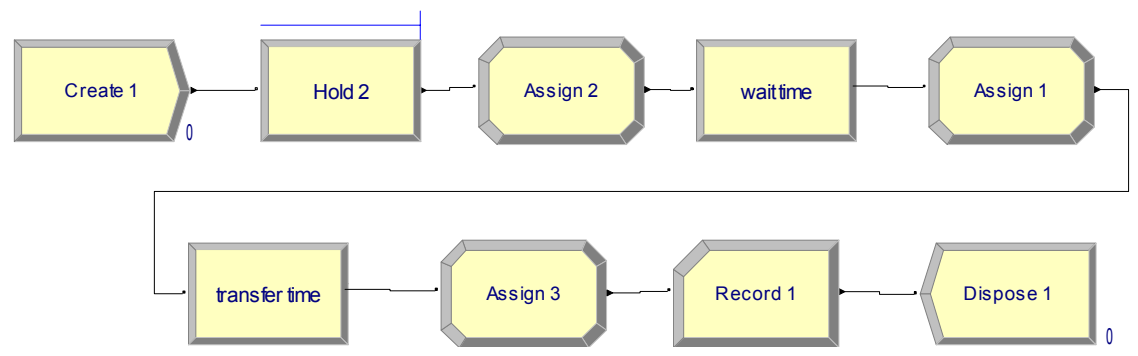

Figure 4: Flow diagram of the parking operations in the refuge area simulator.

The diagram is crossed by the simulator as many times as there are vehicles to park and, with each operation, it updates the values of the variables. Figure 5 lists the operations performed by each block with the meaning (in italics) of each module of the simulator.

The functional expression adopted for the calculation of the parking time $t_{0}$ is extracted from that proposed by Van der Goot [17], which depends on the velocity $v_{r}$ of the vehicles, the distance $l_{r}$ from the parking spaces and the occupation coefficient $x$ of the parking area:

$$
T_{r i c}=\frac{l_{r}}{2 \cdot v_{r}}+t_{\text {man }} \quad t_{o}=8 \cdot T_{r i c} \cdot\left[1-e^{-\left(\frac{400-x}{266,6}\right)^{-17}}\right]
$$

The objective of simulation is evaluation of a generalized cost function (total parking time of the vehicles inside the refuge area). The variable is vehicle position inside the refuge area. The constraints are: 
- $\quad$ capacity $(\mathrm{C})$ of the refuge area (number of vehicles);

- $\quad$ number $(\mathrm{N})$ of vehicles entering the refuge area;

- velocity of vehicles inside the refuge area;

- configuration of the refuge area;

- $\quad$ parking typology (controlled or not);

- manage time.

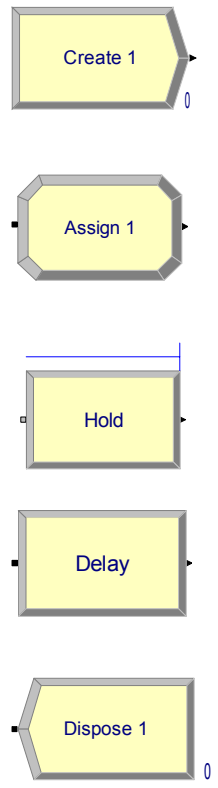

The "Create" module is intended as the starting point for entities in a simulation model. Entities are created using a schedule or based on a time between arrivals. Entities then leave the module to begin the process through the system. The entity type is specified in this module. The numeric index in the module represents the number of entities created. The first block simulates the starting point for vehicles in the simulation model.

The "Assign" module is used for assigning new values to variables, entity attributes, entity types, entity pictures, or other system variables. Multiple assignments can be made with a single Assign module.

The blocks "Assign1", "Assign2" and "Assign3" are exclusively for updating values of intermediary variables introduced.

The "Hold" module will hold an entity in a queue to wait for a signal, wait for a specified condition to become true (scan), or be held infinitely (to be removed later with the Remove module).

The blocks "Hold2" simulate wait of vehicles to transfer onto the parking spaces.

The "Delay" module delays an entity by a specified amount of time. When an entity arrives at a Delay module, the time delay expression is evaluated and the entity remains in the module for the resulting time period.

The blocks "Waittime" and "Transfertime" simulate waiting time required to search for a parking space and transfer time required to move onto the parking space.

The "Dispose" module is intended as the end point for entities in a simulation model. Entity statistics may be recorded before the entity is disposed. The numeric index in the module represents the number of entities leaving.

The last blocks simulate the end of parking for vehicles in the simulation model.

Figure 5: $\quad$ Operations performed in each simulator block.

\section{Experimentation}

The data for the calibration were obtained from a real experiment conducted in the urban area of Melito Porto Salvo in the province of Reggio Calabria (Italy). The refuge area, about $1.5 \mathrm{~km}$ from the centre of Melito Porto Salvo, has a total surface area of $3100 \mathrm{~m}^{2}$, with a capacity of about 120 vehicles (Figures 6, 7).

The characteristic times (Tab. 2) of evacuation onto the refuge area are obtained by survey cameras positioned in the refuge area.

\section{Application}

Evacuation produces temporary oversaturation of some supply components and creation/dispersion of queues, in particular upcoming the refuge area. To analyse this event it is necessary to define two problems: access to the refuge area; the refuge area's internal parking organization. 


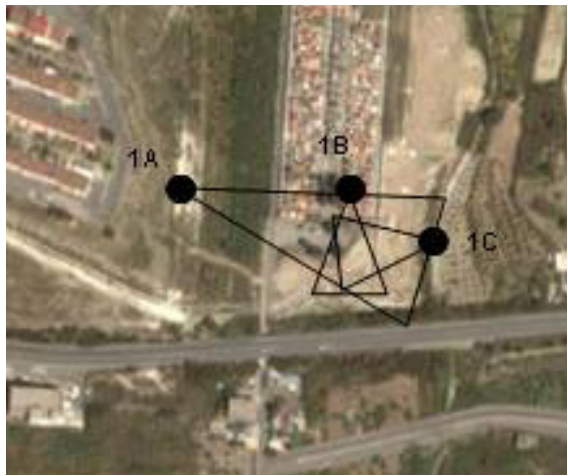

Figure 6: Refuge area and positions for the survey cameras in the area itself.

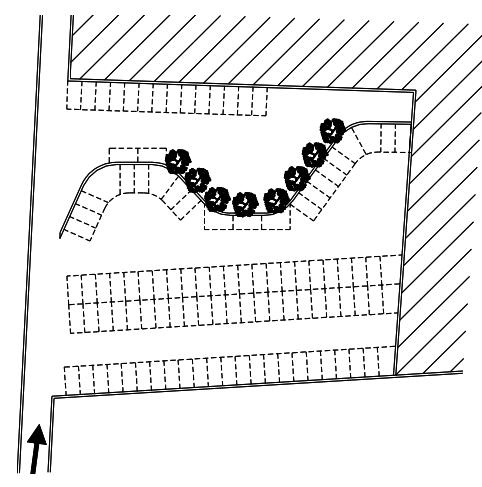

Figure 7: Plan of the internal organization (parking spaces) in the refuge area.

Table 2: $\quad$ Characteristics of refuge area access.

\begin{tabular}{lc}
\hline \multicolumn{1}{c}{ Description } & Clock time \\
\hline alarm time & $10 \mathrm{~h} 14 \mathrm{~m}$ \\
first vehicle arrival time inside refuge area & $10 \mathrm{~h} 40 \mathrm{~m}$ \\
first pedestrian arrival time inside refuge area & $10 \mathrm{~h} 59 \mathrm{~m}$ \\
civil protection arrival time inside refuge area & $11 \mathrm{~h} 10 \mathrm{~m}$ \\
\hline
\end{tabular}

The inputs for the application are the upcoming flows to the refuge area; these data are obtained from supply-demand interaction $[14,15]$. Link capacity used by vehicles to access the refuge area is obtained by specification, calibration and validation of models in [14]. Application of the models shows that the flows entering the refuge area have ordinary values, and thus do not cause conditions of temporary vehicle oversaturation (Figure 8).

In transport networks, various functions may be used to relate travel time $c$ or speed $v$ on the link to vehicle flow $f$, capacity $C$ and other characteristics.

The hypothesis for the simulation is that the number of entry vehicles is equal to refuge area capacity (120 parking spaces). In the simulation there are two different scenarios:

- uncontrolled parking: random parking of the vehicles inside the refuge area;

- controlled parking: the vehicles park inside the refuge area in the most distant parking space (system optimum).

The internal parking organization in the refuge area does not produce queuing to access the area, the average vehicle parking time being equivalent to the experimental time detected. In particular, vehicle parking time and vehicle waiting time are respectively $50 \%$ and $75 \%$ lower in the controlled parking scenario than the uncontrolled parking scenario. 


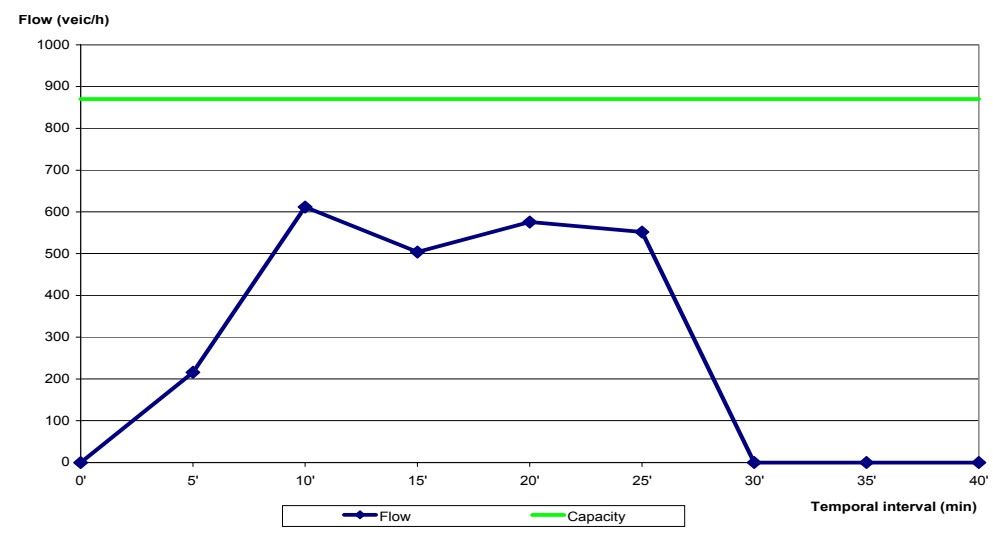

Figure 8: Correlation between upcoming flows and link capacity.

\section{Conclusions and perspectives}

The main results of this paper are first a selection of models proposed in the literature for terminal simulation: there are no specific models to simulate emergency conditions and in particular refuge areas. This paper deals with the specification, calibration, validation and testing of models to simulate and design a refuge area.

Our experimentation is applied to the real case of the town of Melito Porto Salvo (Italy), yielding good results in model calibration. Application of the models showed that the upcoming flows to the refuge area have ordinary values, and thus do not cause conditions of temporary vehicle oversaturation. The internal parking organization of refuge's area don't produce queues phenomena to access in the area and the average vehicle parking time is equivalent to the experimentation measured time.

Further developments of the paper are the extension with more relieved data, the possibility of modifying the refuge's area internal organization (what to) and a different access distribution of the vehicles to the refuge's area.

\section{References}

[1] Legge 24 febbraio 1992 n. 225, Istituzione del Servizio nazionale della protezione civile, Gazzetta Ufficiale, no. 64

[2] Russo, F. \& Vitetta, A., Risk evaluation in a transportation system, in Di Gangi, M. (ed.), Modelli e metodi per l'analisi delle reti di trasporto in condizioni di emergenza: contribute metodologici ed applicative, EditricErmes, ISBN 88-87687-70-6, 2005

[3] Goldblatt, R., Development of evacuation time estimates for the Davis nuclear power station, Tech. Rep. 329 KLD, 1993

[4] Russo, F. \&Vitetta, A., The road network design problem to improve the safety during exogenous flow perturbations, Proceedings of the 29th ISATA Conference Florence, 1996 
[5] Goldblat, R., Evacuation planning. Human factor and traffic engineering perspectives, Proceedings of the European Transport Conference, Strasbourg, 2004

[6] University of Maryland, Fire and Rescue Institute, http://www.mfri.org, 2005

[7] Di Gangi, M., Luongo, A. \& Polidoro, R., Una procedura di carico dinamico per la valutazione dei piani di evacuazione, Proceedings of 2 nd Scientific Seminar on Methods and Technologies of Transportation Engineering, Università di Reggio Calabria, Franco Angeli, Milan, 2000

[8] Ben Akiva, M. \& Lerman, S., Discrete choice analysis: theory and application to travel demand, MIT Press, Cambridge, MA, 1985

[9] Sheffi, Y., Urban transportation networks, Prentice Hall, Englewood Cliff, NJ, 1985

[10] Train, K., Discrete choice methods with simulation, MIT Press Cambridge, Massachusetts, 2003

[11] Cascetta, E., Transportation systems engineering: theory and methods, Kluwer Academic Press, 2001

[12] Kelton W. D., Sadowski R. P. \& Sturrock, D. T., Simulation with Arena, Third Edition, McGraw Hill, 2004

[13] Lieberman, E. \& Rathi, A. K., Traffic Simulation, Chapter 10 in Traffic Flow Theory, Oak Ridge National Laboratory, 1997

[14] Vitetta, A., Musolino, G. \& Marcianò, F.A., Safety of users in road evacuation: supply and supply-demand interaction models for users, Proceedings of Sustainable Development Conference, Algarve, 2007

[15] Russo, F. \& Chilà, G., Safety of users in road evacuation: demand models, Proceedings of Sustainable Development Conference, Algarve, 2007

[16] Rockwell Software, Arena User's Guide, ID ARENA-UM001A-EN-P, United States of America, 2004

[17] Van der Goot, D., A model to describe the choice of parking places, Transp. Research, vol. 16A, no.2, Pergamon Press, Washington (USA), 1982 